\title{
Characterization of a Biofilm Bioreactor Designed for the Single-Step Production of Aerial Conidia and Oosporein by Beauveria bassiana PQ2
}

\author{
Héctor Raziel Lara-Juache ${ }^{1}$, José Guadalupe Ávila-Hernández ${ }^{2}$, Luis Víctor Rodríguez-Durán ${ }^{3, *(D),}$ \\ Mariela Ramona Michel ${ }^{1}$, Jorge Enrique Wong-Paz ${ }^{1}$, Diana Beatriz Muñiz-Márquez ${ }^{1}$, Fabiola Veana ${ }^{1}$, \\ Mayra Aguilar-Zárate ${ }^{4}$ (D) Juan Alberto Ascacio-Valdés ${ }^{5}$ (D) and Pedro Aguilar-Zárate ${ }^{1, *}(\mathbb{D}$
}

1 Departamento de Ingenierías, Instituto Tecnológico de Ciudad Valles, Tecnológico Nacional de México, Carretera al Ingenio Plan de Ayala Km. 2, Colonia Vista Hermosa, Ciudad Valles,

San Luis Potosí C.P. 79010, Mexico; 15690303@tecvalles.mx (H.R.L.-J.); mariela.michel@tecvalles.mx (M.R.M.); jorge.wong@tecvalles.mx (J.E.W.-P.); diana.marquez@tecvalles.mx (D.B.M.-M.); fabiola.veana@tecvalles.mx (F.V.)

2 Facultad de Estudios Profesionales Zona Huasteca, Universidad Autónoma de San Luis Potosí, Romualdo del Campo, No. 501, Rafael Curiel, Ciudad Valles, San Luis Potosí C.P. 79060, Mexico; jose94guada@hotmail.com

check for updates

Citation: Lara-Juache, H.R.;

Ávila-Hernández, J.G.;

Rodríguez-Durán, L.V.; Michel, M.R.; Wong-Paz, J.E.; Muñiz-Márquez, D.B.; Veana, F.; Aguilar-Zárate, M.; Ascacio-Valdés, J.A.; Aguilar-Zárate, P. Characterization of a Biofilm Bioreactor Designed for the Single-Step Production of Aerial Conidia and Oosporein by Beauveria bassiana PQ2. J. Fungi 2021, 7, 582. https://doi.org/10.3390/jof7080582

Academic Editors: Laurent Dufossé and Craig Faulds

Received: 1 June 2021

Accepted: 19 July 2021

Published: 21 July 2021

Publisher's Note: MDPI stays neutral with regard to jurisdictional claims in published maps and institutional affiliations.

Copyright: (C) 2021 by the authors. Licensee MDPI, Basel, Switzerland. This article is an open access article distributed under the terms and conditions of the Creative Commons Attribution (CC BY) license (https:// creativecommons.org/licenses/by/ $4.0 /)$
3 Unidad Académica Multidisciplinaria Mante, Universidad Autónoma de Tamaulipas, E. Cárdenas González No. 1201, Jardín, Ciudad Mante, Tamaulipas C.P. 89840, Mexico

4 Facultad de Ciencias Químicas, Universidad Autónoma de San Luis Potosí, Av. Dr. Manuel Nava 6 , Zona Universitaria, San Luis Potosí, San Luis Potosí C.P. 78290, Mexico; mayra.aguilar@uaslp.mx

5 Facultad de Ciencias Químicas, Universidad Autónoma de Coahuila, Boulevard Venustiano Carranza s/n, República Oriente, Saltillo, Coahuila C.P. 25280, Mexico; alberto_ascaciovaldes@uadec.edu.mx

* Correspondence: luis.duran@docentes.uat.edu.mx (L.V.R.-D.); pedro.aguilar@tecvalles.mx (P.A.-Z.)

Abstract: Beauveria bassiana is an entomopathogenic fungus that is used for the biological control of different agricultural pest insects. B. bassiana is traditionally cultivated in submerged fermentation and solid-state fermentation systems to obtain secondary metabolites with antifungal activity and infective spores. This work presents the design and characterization of a new laboratory-scale biofilm bioreactor for the simultaneous production of oosporein and aerial conidia by B. bassiana PQ2. The reactor was built with materials available in a conventional laboratory. $K_{L} a$ was determined at different air flows (1.5-2.5 L/min) by two different methods in the liquid phase and in the exhaust gases. The obtained values showed that an air flow of $2.5 \mathrm{~L} / \mathrm{min}$ is sufficient to ensure adequate aeration to produce aerial conidia and secondary metabolites by B. bassiana. Under the conditions studied, a concentration of $183 \mathrm{mg}$ oosporein per liter and $1.24 \times 10^{9}$ spores per gram of support was obtained at $168 \mathrm{~h}$ of culture. These results indicate that the biofilm bioreactor represents a viable alternative for the production of products for biological control from B. bassiana.

Keywords: Beauveria bassiana; biological control; oosporein; spore production

\section{Introduction}

The production of spores and metabolites, such as antibiotics, enzymes, and pigments from filamentous fungi, has taken on global importance for the biological control of pests and biotechnological purposes [1-5]. These metabolites have been produced using fermentation systems, such as submerged fermentation $(\mathrm{SmF})$ and solid-state fermentation (SSF), which differ in the nature of their operating conditions [6-9]. Traditionally, both processes (SmF and SSF) are vital for industrial spore production. SmF is used for the production of biomass and mycelium that will be inoculated into the solid substrate in SSF [10].

Beauveria bassiana is an entomopathogen and endophyte fungi used as a biocontrol agent against pest insects as a spore formulation $[3,11]$. It also produces enzymes and secondary metabolites, such as bassianin, tenellin, beauvericin, bassiacridin, and oosporein; 
this last one has been characterized as a soluble red pigment with the formula $\mathrm{C}_{14} \mathrm{H}_{10} \mathrm{O}_{8}$, and there is great scientific interest in mass producing it for biotechnological applications $[12,13]$.

The in vivo production of a reddish coloration has been reported in Musca domestica (L.) at the end of infection by B. bassiana attributed to oosporein [14] as the principal molecule responsible for immune host suppression [15]. This molecule has attracted attention for its antimicrobial activities against bacterial and fungal phytopathogens $[13,16,17]$, but it also exhibits cytotoxic properties $[12,13,18]$. Conversely, it has been observed that the use of fermented crude extracts (raw secondary metabolites) of $B$. bassiana benefits plant growth, inhibits the development of diseases caused by plant pathogenic fungi, and contributes to the production of phenolic compounds [5]. Instead of the use of synthetic insecticides and fungicides, biological control using spores and even metabolites represent a safe and feasible alternative for the control of pests [19], but production systems should be developed to obtain quality products. Currently, biofilm reactors represent a formidable strategy that combines SmF and SSF in one apparatus for the production of spores, biomass, and secondary metabolites [20]. The attachment of aerial hyphae to the inert support and the release of secondary metabolites to the medium, similar to natural development, give a better yield and quality of conidia [21], while the inert support can be reused, making it simple, user friendly, and inexpensive [6]. However, in a bioreactor system, many parameters should be determined, one of the most important being the volumetric mass transfer coefficient $\left(K_{L} a\right)$, to establish the aeration efficiency during the aerobic bioprocess that depends on the shape, size, agitation speed, air flow rate, etc. of the reactor, but not on its volume [21,22]. The measurement of microbial growth is also a concern. Measuring microbial growth in solid fermentation is a difficult task due to the adhesion of the biomass to the solid support. Therefore, the measurement of $\mathrm{CO}_{2}$ production is a feasible method for its estimation [23].

The aims of the current study were as follows: to design and characterize a biofilm bioreactor for the production and recovery of aerial conidia and oosporein by Beauveria bassiana at lab scale and to evaluate the fungal growth by monitoring the $\mathrm{CO}_{2}$ production.

\section{Materials and Methods}

\subsection{Fungal Strain and Media}

The Beauveria bassiana PQ2 strain was obtained from the Food Analysis Laboratory, Instituto Tecnológico de Ciudad Valles, Ciudad Valles, San Luis Potosí, México. The fungal strain was cryopreserved using glycerol and skimmed milk at $-20^{\circ} \mathrm{C}$ and reactivated in potato-dextrose agar medium for seven days at $27^{\circ} \mathrm{C}$.

\subsection{Biofilm Reactor Setup}

The whole bioprocess was carried out in a low-cost lab-made biofilm reactor (Figure 1). The biofilm reactor consisted of a wide-mouth glass bottle with $1300 \mathrm{~mL}$ capacity (Schott Duran GLS 80, Mainz, Germany) and a $20 \mathrm{~g}$ stainless-steel pad (Scotch-Brite, 3 M, St. Paul, MN, USA) as inert support added to the bottle headspace (Figure 1). Air was supplied by an air pump. The medium was recirculated by a peristaltic pump (CRODE, Celaya, Mexico). 


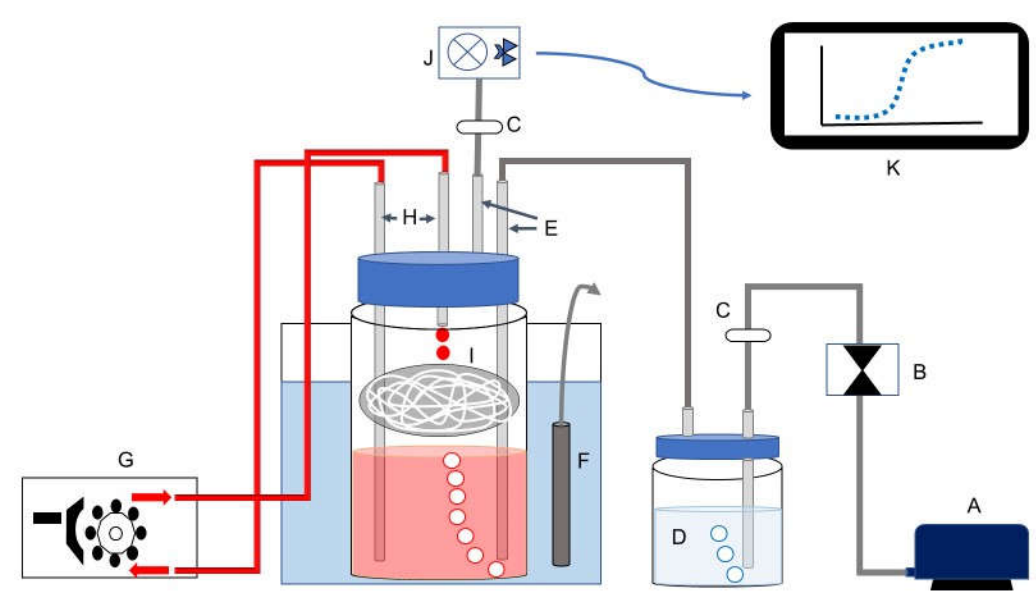

Figure 1. Scheme of biofilm bioreactor designed: (A) air pump; (B) air flow control; (C) air filter; (D) external bubbler; (E) air inlet and outlet; (F) thermostat; $(\mathrm{G})$ peristaltic pump; $(\mathrm{H})$ culture medium inlet and outlet; (I) inert support (metal structure packing); (J) wireless $\mathrm{CO}_{2}$ sensor; (K) LabQuest interface for data recovery. The samples were taken at the culture media inlet port.

Volumetric oxygen transfer coefficients $\left(K_{L} a\right)$ were determined by three repetitions in both liquid and gaseous phases at three air flow rates $\left(1.5,2.0\right.$, and $\left.2.5 \mathrm{~L} \mathrm{~min}^{-1}\right)$ at $30 \pm 2{ }^{\circ} \mathrm{C}$. For the liquid phase, the sodium sulfite oxidation method was used [24]. A solution composed of $600 \mathrm{~mL}$ of $\mathrm{Na}_{2} \mathrm{SO}_{3}(0.5 \mathrm{~N})$ and $\mathrm{CuSO}_{4} 0.001 \mathrm{M}$ was used. The air inlet at different flow rates was started, and $2 \mathrm{~mL}$ samples from the solution were obtained in intervals of $1-8 \mathrm{~h}$. To each sample, $3 \mathrm{~mL}$ of iodine $(0.5 \mathrm{~N})$ was added, and a titration with $\mathrm{Na}_{2} \mathrm{~S}_{2} \mathrm{O}_{3}(0.06 \mathrm{~N})$ was performed applying a starch solution (10\%) as indicator. $K_{L} a$ was obtained using Equation (1):

$$
K_{L} a=\frac{1}{C^{*}} \times \frac{m \times N}{4 \times V m} .
$$

where $C^{*}$ is the $\mathrm{O}_{2}$ solubility, $\mathrm{N}$ is the concentration of $\mathrm{Na}_{2} \mathrm{SO}_{3}, \mathrm{Vm}$ is the volume of sample of $\mathrm{Na}_{2} \mathrm{SO}_{3}$, and $m$ is the slope obtained by linear regression (Figure $\mathrm{S} 1$ ).

For the gaseous phase, air flows of 1.5, 2.0, and $2.5 \mathrm{~L} \mathrm{~min}^{-1}\left(F_{\mathrm{O} 2}^{\text {in }}\right)$ were tested using the gaseous $\mathrm{O}_{2}$ sensor (Vernier, Beaverton, OR, USA) at the output flow ( $F^{\text {out }} \mathrm{O} 2$ ) in a solution composed of $600 \mathrm{~mL}$ of $\mathrm{Na}_{2} \mathrm{SO}_{3}(0.5 \mathrm{~N})$ and $\mathrm{CuSO}_{4}(0.001 \mathrm{M})$ [25]. Samples from $\mathrm{O}_{2}$ were taken every $5 \mathrm{~min}$ for $480 \mathrm{~min}$. After $480 \mathrm{~min}$, the dissolved oxygen was determined by the Winkler method. The data obtained by the sensor and the Winkler method were used to obtain the gaseous phase balance with Equation (2):

$$
K_{L} a=\frac{F_{O 2}^{\text {in }}-F_{O 2}^{\text {out }}}{V \times\left(C^{*}-C_{L}\right)} .
$$

where $\mathrm{F}_{\mathrm{O} 2}^{\text {in }}$ is the molar flow rate of oxygen gas input, $\mathrm{F}_{\mathrm{O} 2}^{\mathrm{out}}$ is the molar outflow of oxygen gas, $V$ is the reactor volume, $C_{L}$ is the dissolved oxygen concentration in liquid phase, and $C^{*}$ is the oxygen saturation concentration.

\subsection{Fungal Growth Evaluation, Aerial Conidia, and Red Pigment Production Dynamics}

Submerged fermentation was carried out in two lab-made biofilm reactors $(1300 \mathrm{~mL})$ with $600 \mathrm{~mL}$ of Czapek-Dox mineral medium (sucrose $22.5 \mathrm{~g} / \mathrm{L}$, yeast extract $6.0 \mathrm{~g} / \mathrm{L}$, $\mathrm{KH}_{2} \mathrm{PO}_{4} 0.48 \mathrm{~g} / \mathrm{L}, \mathrm{MgSO}_{4} 0.72 \mathrm{~g} / \mathrm{L}, \mathrm{NH}_{4} \mathrm{NO}_{3} 0.06 \mathrm{~g} / \mathrm{L}$, and $\mathrm{CaCl}_{2} 0.24 \mathrm{~g} / \mathrm{L}$ ) at $\mathrm{pH}$ of 6.0. The culture medium was autoclaved at $121^{\circ} \mathrm{C}$ for $15 \mathrm{~min}$ and inoculated with Beauveria bassiana PQ2 at $1 \times 10^{6}$ spores $/ \mathrm{mL}$. Growth and pigment production were carried out in the following conditions: temperature of $30 \pm 2{ }^{\circ} \mathrm{C}$, air flow rate of $2.5 \mathrm{~L} / \mathrm{min}$, medium recirculation of $3.66 \mathrm{~L} / \mathrm{min}(20 \mathrm{~min}$, every $12 \mathrm{~h}$ ), and duration of $168 \mathrm{~h}$ in the biofilm 
reactor for three repetitions. The oosporein and aerial conidia were monitored in the two bioreactors, while $\mathrm{CO}_{2}$ evolution data were obtained from only one bioreactor.

Microbial growth was estimated indirectly by $\mathrm{CO}_{2}$ production in the exit gases using a Go Direct ${ }^{\circledR} \mathrm{CO}_{2}$ analyzer (Vernier, Beaverton, OR, USA) controlled by LabQuest2 interface. The data generated show the $\mathrm{CO}_{2}$ production rate (Figure 2). The $\mathrm{CO}_{2}$ production rate was integrated to obtain the $\mathrm{CO}_{2}$ production. The $\mathrm{CO}_{2}$ production was modeled as biomass ( $\mathrm{mg} \mathrm{CO} 2 / \mathrm{mL}$ of liquid media) by the Verlhurts-Pearl logistic model following the method proposed by Aguilar-Zárate et al. [26] (Equation (3)):

$$
\frac{d \mathrm{CO} 2}{d t}=\mu \mathrm{CO} 2\left[1-\frac{\mathrm{CO} 2}{\mathrm{CO} 2_{\max }}\right]
$$

where $\mu$ is the maximal specific $\mathrm{CO}_{2}$ production rate and $\mathrm{CO}_{2 \max }$ is the equilibrium value for $\mathrm{CO}_{2}$ with $d \mathrm{CO} 2 / d t=0$. The solution to Equation (3) is shown as Equation (4):

$$
\mathrm{CO}_{2}(t)=\frac{\mathrm{CO}_{2} \text { max }}{1-\left(\frac{\mathrm{CO} 2_{\max }-\mathrm{CO}_{0}}{\mathrm{CO} 2_{0}}\right) e^{-\mu t}}
$$

$\mathrm{CO}_{0}$ is the value of $\mathrm{CO}_{2}$ when $t=0$. Square error values were minimized as a function of $\mathrm{CO}_{\max }, \mathrm{CO}_{0}$, and $\mu$.

Samples were taken every $24 \mathrm{~h}$ to the end of fermentation, and oosporein and sugar concentrations were measured. Sugar consumption was measured by refractometry since the sucrose was the carbon source. Oosporein analyses were carried out by spectrophotometry as follows. Samples were filtered through a sterile Millipore membrane $(0.45 \mu \mathrm{m})$ (Minisart, Sartorius Stedim Biotech, Aubagne, France) and evaluated by spectrophotometer at the wavelength of $430 \mathrm{~nm}$. Data were compared against a standard calibration curve of oosporein (0-31.25 ppm, purity $\geq 70 \%$ ) provided by the Food Analysis Laboratory. The pigment production kinetics was modeled using the Luedeking-Piret model according to Aguilar-Zarate et al. [27] with Equation (5):

$$
\frac{d_{\mathrm{Oosp}}}{d t}=Y_{\mathrm{Oosp} / \mathrm{CO} 2} \frac{d_{\mathrm{CO} 2}}{d_{t}}+k \mathrm{CO} 2
$$

where $Y_{\mathrm{Oosp} / \mathrm{CO} 2}$ is the production coefficient and $k(\mathrm{mg} / \mathrm{h} \mathrm{mg})$ is the secondary coefficient of oosporein production $(k>0)$ or destruction $(k<0)$. The solution to the previous equation is given below (Equation (6)):

$$
\mathrm{Oosp}=\mathrm{Oosp} p_{0}+\mathrm{Oosp}_{\mathrm{Oosp} / \mathrm{CO} 2}\left(\mathrm{CO} 2-\mathrm{CO} 2_{0}\right)+\frac{k \mathrm{CO} 2_{\max }}{\mu} \ln \left[\frac{\mathrm{CO} 2_{\max }-\mathrm{CO} 2_{0}}{\mathrm{CO} 2-\mathrm{CO} 2_{0}}\right]
$$

with $\operatorname{Oosp}_{0}$ being the value for oosporein when $\mathrm{CO}_{2}=\mathrm{CO}_{0}$.

The conidia production was evaluated at the end of the fermentation through the recovery from the metal solid support of the biofilm reactor with a diluted sterile $0.01 \%$ $(v / v)$ Tween 80 solution. The fungal conidia were counted with a Neubauer chamber using a light microscope at $40 \times$, and the spore yield was obtained by applying Equation (7):

$$
\frac{\text { COnidia }}{\text { gof support }}=\left(\frac{\text { Spores }}{m L}\right) \times \frac{\text { Volume in suspension of conidia recovered }}{\text { gof support }}
$$

\subsection{Oosporein Characterization by HPLC Tandem Mass Spectrometry}

The filtered total aqueous extract at the final point of fermentation was analyzed by reversed-phase high-performance liquid chromatography (HPLC) equipped with an autosampler (Varian ProStar 410, Walnut Creek, CA, USA), ternary pump (Varian ProStar 230I, USA), and PDA detector (Varian ProStar 330, USA). A sample ( $5 \mu \mathrm{L})$ was injected into a Denali C-18 column ( $150 \mathrm{~mm} \times 2.1 \mathrm{~mm}, 3.1 \mu \mathrm{m}$, Grace, Deerfield, IL, USA). The oven temperature was $30^{\circ} \mathrm{C}$. The elution gradient was formic acid $(0.2 \% v / v$, solvent $\mathrm{A})$ 
and acetonitrile (solvent B) with initial gradient course of 3\% B, 5-15 min; 16\% B linear, $15-45 \mathrm{~min}$; and $50 \% \mathrm{~B}$ linear. The flow rate was $0.2 \mathrm{~mL} / \mathrm{min}$ and the elution was monitored at $287 \mathrm{~nm}$. Liquid chromatography-ion trap mass spectrometry (Varian 500-MS IT Mass Spectrometer, USA) equipped with an electrospray ion source was used. The MS analysis was performed in the negative mode $[\mathrm{M}-\mathrm{H}]^{-1}$ using nitrogen as the nebulizing gas and helium as the damping gas. The parameters of the ion source were as follows: spray voltage of $5.0 \mathrm{kV}$, capillary voltage of $90.0 \mathrm{~V}$, and temperature of $350^{\circ} \mathrm{C}$. Full scan spectra were acquired in the $\mathrm{m} / \mathrm{z}$ range 100-2000, and, subsequently, the MS/MS analyses were performed on a series of selected ions. The data were collected and processed using MS Workstation software (V 6.9).

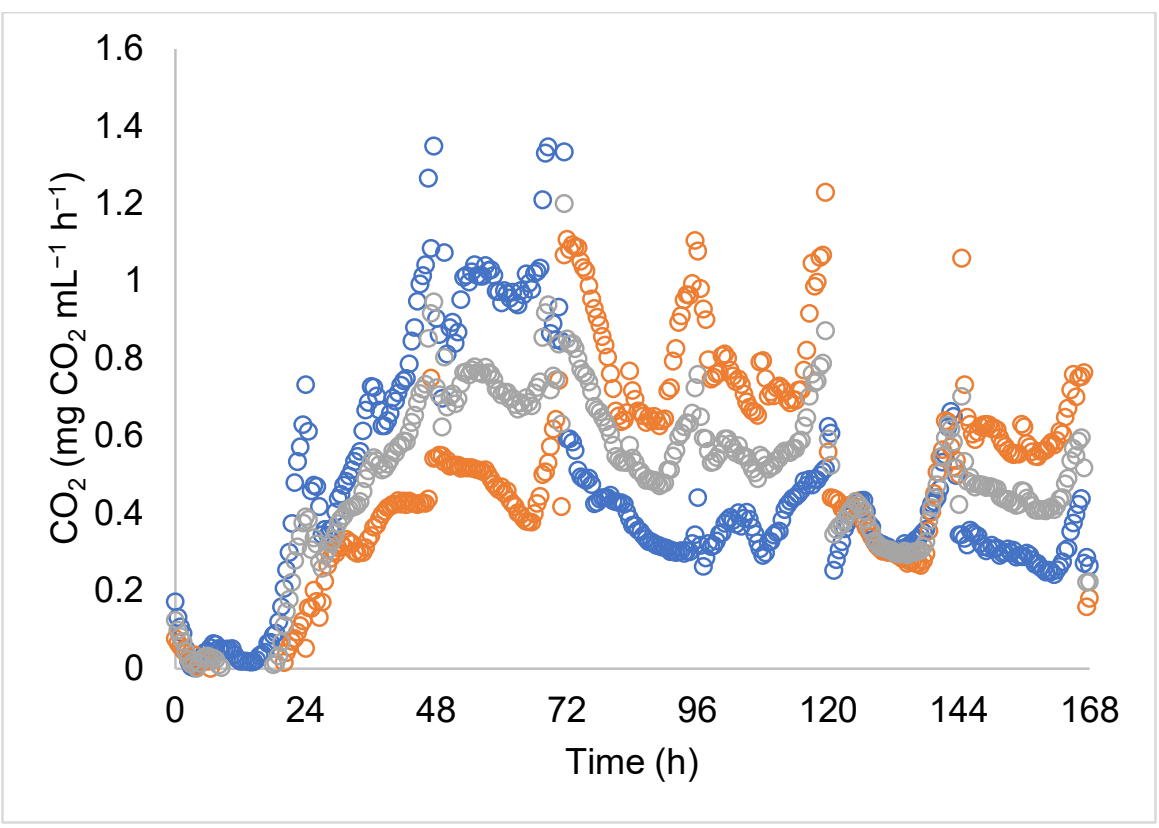

Figure 2. Evolution of $\mathrm{CO}_{2}$ production during fermentation of Beauveria bassiana PQ2 for the production of aerial conidia and oosporein. The different colors of open circles are the repetitions.

\subsection{Statistical Analysis}

The biofilm reactor setup experiments were performed with three repetitions, and the results are presented as mean $\pm \mathrm{SD}$. A post hoc analysis was carried out by Tukey test $(p=0.05)$ for comparing the significant differences between airflow rates.

\section{Results}

The determination of $K_{L} a$ by the sodium sulfite oxidation method for both liquid and gaseous phases allowed the characterization of the biofilm reactor. Table 1 shows that $2.5 \mathrm{~L} / \mathrm{min}$ represents the best flow rate for aeration conditions in both solid and gaseous phases.

Table 1. Bioreactor gas transfer in liquid and gaseous phases.

\begin{tabular}{|c|c|c|}
\hline Flow Rate (L/min) & $K_{L} a$ Liquid Phase $\left(\min ^{-1}\right)$ & $K_{L} a$ Gaseous Phase $\left(\min ^{-1}\right)$ \\
\hline 1.5 & $0.99 \pm 0.009 \mathrm{~b}$ & $0.51 \pm 0.261 \mathrm{~b}$ \\
\hline 2.0 & $1.16 \pm 0.017 \mathrm{~b}$ & $0.58 \pm 0.102 b$ \\
\hline 2.5 & $2.10 \pm 0.017 \mathrm{a}$ & $3.66 \pm 0.394 \mathrm{a}$ \\
\hline
\end{tabular}

Different letters indicate significant differences (Tukey test, $p=0.05$ ).

In regard to the respiration activity of $B$. bassiana throughout $\mathrm{CO}_{2}$ analysis, Figure 2 shows the evolution of $\mathrm{CO}_{2}$ production along the fermentation process. A similar pattern in $\mathrm{CO}_{2}$ evolution was seen during the $0-96 \mathrm{~h}$ period when submerged fermentation developed. 
High variation was observed during the $96-168 \mathrm{~h}$ period due to the high respiratory activity mainly in the solid-state culture. At 48 and $69 \mathrm{~h}$, a higher $\mathrm{CO}_{2}$ production rate was observed (1.35 $\mathrm{mg}$ of $\mathrm{CO}_{2}$ per $\mathrm{mL}$ of media per hour). The maximal production rate was $80.59 \mathrm{mg}$ $\mathrm{CO}_{2} \mathrm{~mL}^{-1}$ (Table 2) at $168 \mathrm{~h}$ of culture (Figure 3). It could be considered that the maximal growth rate was reached at this stage [6]. The accumulated $\mathrm{CO}_{2}$ is shown in Figure 3, and the data were obtained from the integration of the $\mathrm{CO}_{2}$ evolution. The graph shows the microbial growth trend at a growth rate of $\mu=0.04 \mathrm{~h}^{-1}$ as follows: At $24 \mathrm{~h}$, a lag phase was found as the entire fermentation process (liquid and solid) began biomass formation on the inert support at $50 \mathrm{~h}$. Then, an exponential phase was observed followed by constant sugar consumption until the end of fermentation $(168 \mathrm{~h})\left({ }^{\circ}\right.$ Brix $_{\text {initial }}=4.03,{ }^{\circ}$ Brix $\left._{\text {final }}=0.55\right)$.

Table 2. Kinetic parameters of Beauveria bassiana PQ2 under biofilm bioreactor conditions.

\begin{tabular}{ccc}
\hline Parameters & Units & Value \\
\hline $\mathrm{CO}_{2 \max }$ & $\mathrm{mg} \mathrm{CO}_{2} \mathrm{~mL}^{-1}$ & 80.59 \\
$\mu$ & $\mathrm{h}^{-1}$ & 0.04 \\
Growth model & $\mathrm{R}^{2}$ & 0.99 \\
Oosporein $\max$ & $\mathrm{mgL}^{-1}$ & 183.0 \\
Oosporein productivity & $\mathrm{mg} / \mathrm{L} / \mathrm{h}$ & 1.09 \\
Oosporein model & $\mathrm{R}^{2}$ & 0.97 \\
$Y_{\text {Oosp } / \mathrm{CO} 2}$ & mg Oosporein $/ \mathrm{h} \times \mathrm{mg} \mathrm{CO}_{2}$ & 0.02 \\
Conidia recovery & Conidia/gram of support & $1.24 \times 10^{9}$ \\
\hline
\end{tabular}

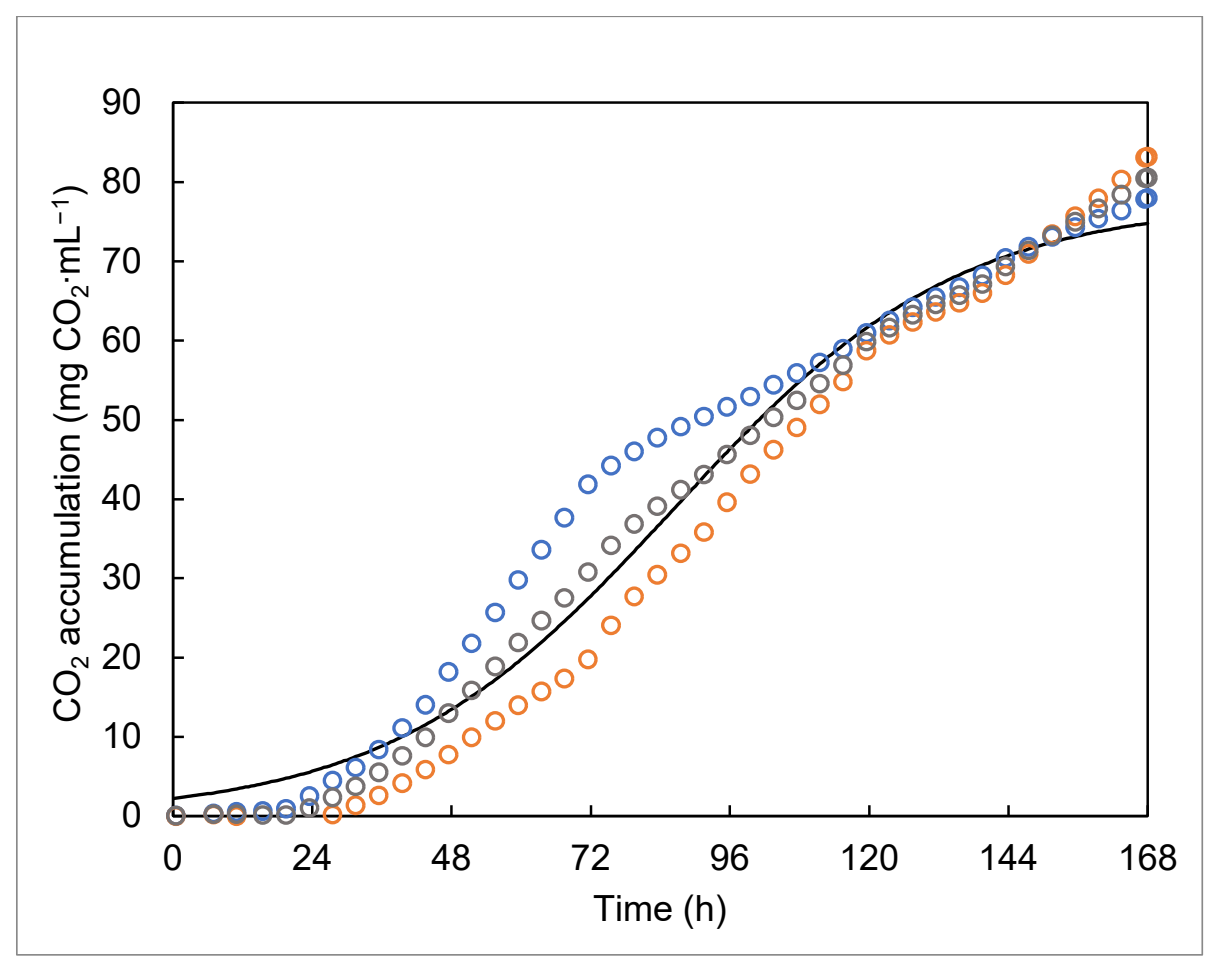

Figure 3. Accumulated $\mathrm{CO}_{2}$ production during fermentation of Beauveria bassiana PQ2 in the bioprocess for the production of aerial conidia and oosporein. Open circles are the experimental data, and the continuous line represents the data calculated by the model.

The production of aerial conidia did not present any problems using the metal structured packing as an inert support (Figure S2), allowing us to obtain $1.24 \times 10^{9}$ conidia/gram of support at $168 \mathrm{~h}$. Although part of the biomass was attached to the walls or internal parts of the biofilm bioreactor, its concentration was not considered in this study. The sterile conditions were confirmed, as there was no contamination of the culture medium. 
The production of the water-soluble pigment oosporein was achieved after $72 \mathrm{~h}$ (Figure 4), reaching a maximum concentration of $183 \mathrm{mg} / \mathrm{L}^{-1}$ at the end of the fermentation. The whole process reached an oosporein productivity of $1.09 \mathrm{mg} / \mathrm{L} / \mathrm{h}$ (Table 2). The oosporein concentration increased over time, as shown in Figure 4. The production of oosporein reached two peaks associated with the growth in SmF and SSF. The first peak was obtained after $96 \mathrm{~h}$ of culture $(42.30 \mathrm{mg} / \mathrm{mL}$ ) (Figure 4). As shown in Figure 2, during $0-96 \mathrm{~h}$, the submerged culture was developed. The second peak was obtained at the end of the fermentation process with $183 \mathrm{mg} / \mathrm{mL}$ of oosporein. The oosporein yield was $0.02 \mathrm{mg}$ of oosporein per hour per mg of $\mathrm{CO}_{2}$.

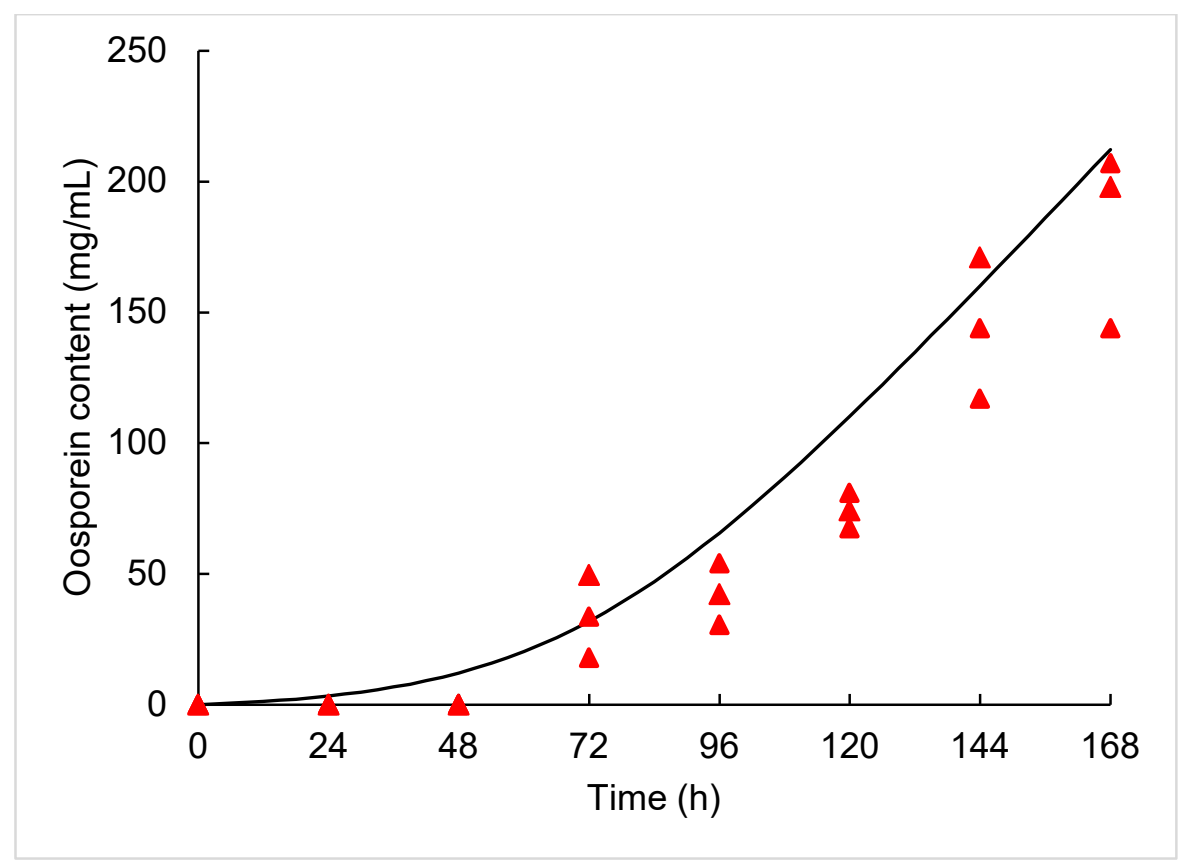

Figure 4. Kinetic production of oosporein by Beauveria bassiana PQ2 in biofilm bioreactor. Closed triangles are the experimental data, and the continuous line represents the data predicted by the model.

Five hundred milliliters of fermented extract were recovered after $168 \mathrm{~h}$ and then submitted to an HPLC-MS/MS analysis in order to characterize the secondary metabolites and corroborate the presence of oosporein produced by B. bassiana PQ2. The results show the presence of five ionized compounds (Figure 5). The fragmentation patterns of the four compounds did not allow the identification of the molecules. Oosporein was found as the major compound in the HPLC chromatogram at a retention time (R. T.) of $22.72 \mathrm{~min}$. It was identified with m/z 305 (306 M. W.) (Table 3).

Table 3. Kinetic parameters of Beauveria bassiana PQ2 under biofilm bioreactor conditions.

\begin{tabular}{cccccc}
\hline Peak No. & $\begin{array}{c}\text { R. T. } \\
(\mathbf{m i n})\end{array}$ & M. W. & $\begin{array}{c}\text { [M-H] } \\
(\mathbf{m} / \mathbf{z})\end{array}$ & MS $^{\mathbf{2}}$ Ion Fragment & $\begin{array}{c}\text { Tentative } \\
\text { Identity }\end{array}$ \\
\hline 1 & 3.40 & 283 & 282 & 150,133 & Unknown \\
2 & 5.92 & 244 & 243 & 200,110 & Unknown \\
3 & 12.84 & 291 & 290 & $254,230,214,200,128$ & Unknown \\
4 & 15.49 & 387 & 386 & $343,299,298,286$ & Unknown \\
5 & 22.72 & 306 & 305 & $277,262,261,249,233,217$, & Oosporein \\
\hline
\end{tabular}

R. T., retention time; M. W., mass weight; $\mathrm{m} / \mathrm{z}$, mass-to-charge ratio; $\mathrm{MS}^{2}$, tandem mass spectrometry. 


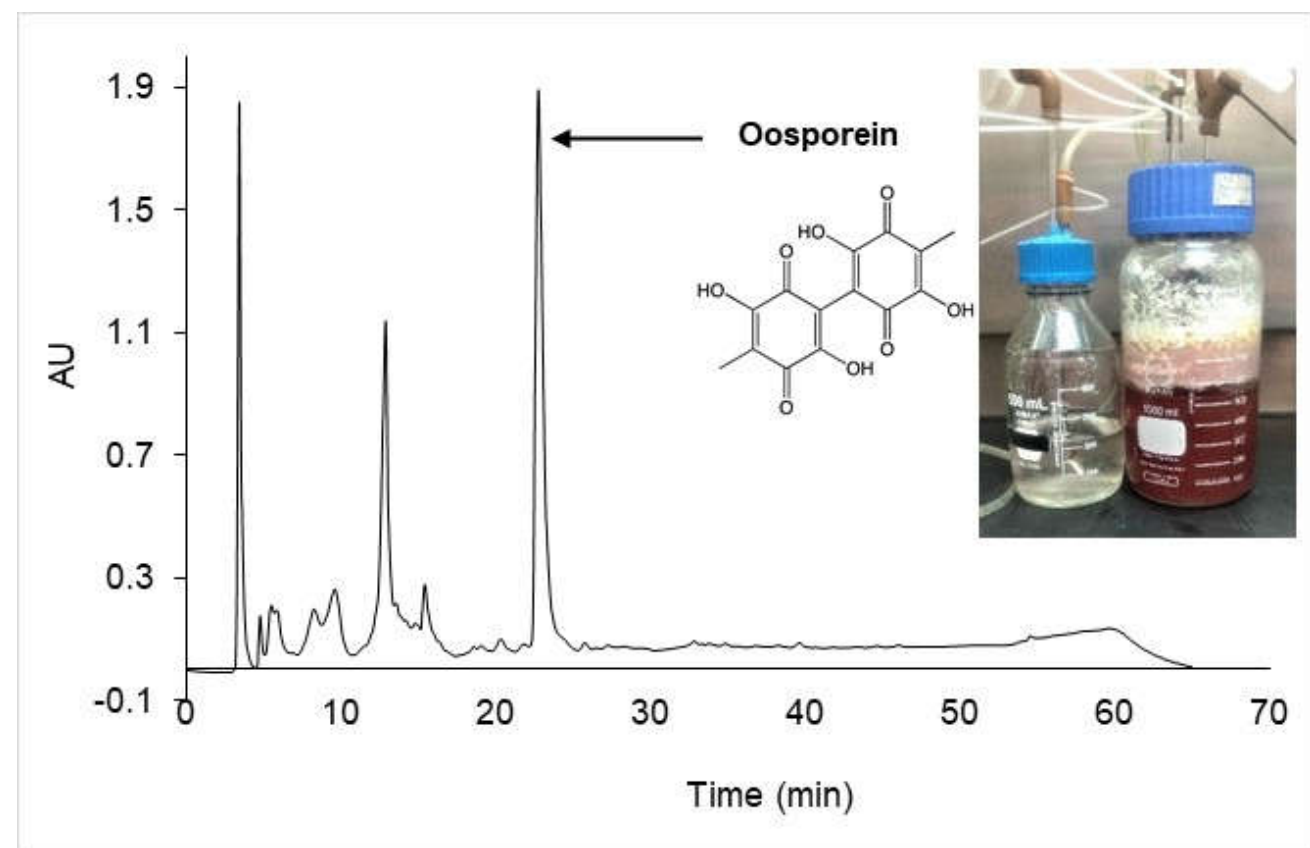

Figure 5. HPLC chromatogram of metabolites produced by B. bassiana PQ2 in the biofilm bioreactor.

\section{Discussion}

Biofilm reactors are a fermentation system for the production of value-added products that combine SmF and SSF approaches, where the biomass adheres to an inert support [28]. In this sense, the availability of oxygen in the solid fermentation (gaseous phase) will be exploited even when there is oxygen saturation in the liquid phase. In addition, the biomass attachment to the support confers some advantages, such as the low viscosity of the medium culture and easy downstream recovery of the products [29].

Oxygen availability is a critical factor for B. bassiana spore production [30-33]. The dissolved oxygen concentration is the result of the oxygen transfer rate (OTR) from the gaseous phase to the liquid phase and the oxygen uptake rate (OUR). The volumetric mass transfer coefficient $\left(K_{L} a\right)$ is a parameter that allows characterizing the capacity of a bioreactor to supply oxygen and is very important for the design, operation, and scaling of bioreactors [34]. Therefore, the $K_{L} a$ of the biofilm bioreactor was determined by two methods, one physical method and one chemical method. Under the operating conditions studied, a $K_{L} a$ value of 0.99 to $2.10 \mathrm{~min}^{-1}$ was obtained by the chemical method, while the physical method obtained values of 0.51 to $3.66 \mathrm{~min}^{-1}$. These values are close to those obtained for a circulating-bed biofilm reactor $\left(0.017 \mathrm{~s}^{-1}\right)$ [35] and higher than those obtained for an up-flow concurrent packed-bed biofilm reactor $\left(0.0013-0.012 \mathrm{~s}^{-1}\right)$ [36]. Furthermore, the $K_{L} a$ values obtained for the biofilm reactor built for this work are within the values $\left(9.5-208 \mathrm{~h}^{-1}\right)$ measured for different commercial stirred-tank bioreactors used for the production of $B$ bassiana blastospores [37].

Hence, the bioprocess using B. bassiana PQ2 was carried out using the aeration flow rate of $2.5 \mathrm{~L} / \mathrm{min}$, which also contributed to the high availability of oxygen at the liquid-gas interface [38].

Respirometry analysis showed the metabolic activity of B. bassiana $\mathrm{PQ} 2$ when adapting to the fermentation conditions (Figure 2). From 48 to $69 \mathrm{~h}, \mathrm{CO}_{2}$ production increased, which was related to mycelial development and the spore yield that improved after $100 \mathrm{~h}$ of the cultivation process $[10,26]$. However, the high variation of $\mathrm{CO}_{2}$ reported in Figure 2 might indicate the need to control the operating conditions, such as temperature, $\mathrm{pH}$, and nutrients; thus, in the future, it will be necessary to optimize them [10]. Figure 3 shows that the microbial growth data were analyzed by non-linear regression. Based on the analysis, the growth rate $(\mu)$ was considered as the parameter to prove that the samples came from the same population. We obtained $\mu=0.040$ with a $95 \%$ of confidence interval of $0.039-0.042$ 
and standard error of 0.001 . The results shown in Figure 3 are similar to those reported by Cruz-Barrera et al. [9] for Trichoderma asperellum Th204 during SSF, who found that the $\mathrm{CO}_{2}$ accumulation indicated the lag phase occurred from 0 to $20 \mathrm{~h}$, the exponential phase from 20 to $80 \mathrm{~h}$, and the stationary phase from 100 to $160 \mathrm{~h}$. Similarly, in the present work, $\mathrm{CO}_{2}$ production was observed even at the end of the process, as the microorganisms continued to grow on the inert support, and it is an indicator of metabolic activity of $B$. bassiana mycelium [39]. Some authors have reported the respiratory activity as an indirect indicator of fungal growth from Aspergillus niger GH1 [26], Trichoderma harzianum IRDT22C [26], Metarhizium anisopliae strain CP-OAX [10], and Metarhizium anisopliae IBCB 425 [40], but there is no information available for Beauveria bassiana.

In the biofilm bioreactor, the presence of conidiophores and spherical conidia attached to the biofilm agglomeration of mycelia on the metal solid support was found. Unlike aerial conidia, blastospores produced in submerged culture had an oval shape and formed fine pellets due to pneumatic agitation. At the end of the fermentation process, the mycelia produced under submerged fermentation were disintegrated, probably by the production of proteases. Once the fermentation process was finished $(168 \mathrm{~h})$, the aerial conidia were harvested from the metal solid support (Figure S2). The yield obtained was $1.24 \times 10^{9}$ conidia/gram, which coincided with the reduction of $\mathrm{CO}_{2}$ production. This condition is similar to that reported by Méndez-González et al. [10] for spore production by M. anisopliae in SSF. In a solid-state culture, results close to those obtained in this study using B. bassiana were reported by Kang et al. [30] using a packed-bed bioreactor. They achieved 1.1-1.2 $\times 10^{10} \mathrm{~g}^{-1}$ and $1 \times 10^{9}$ conidia/g on grain substrates [41] and $5.0 \times 10^{8}$ spores $\mathrm{g}^{-1} \mathrm{dry}$ matter using rice husk [42]. These results serve as a comparison for the yield achieved from B. bassiana in SSF, indicating the biofilm bioreactor is a feasible tool for the production of conidia.

The pigment production is consistent with that reported by Ávila Hernández et al. [43], who mentioned that oosporein is the major pigment produced by Beauveria bassiana under submerged fermentation, which shows antimicrobial and insecticidal activities. The yield obtained $\left(183 \mathrm{mg} / \mathrm{L}^{-1}\right)$ is close to the $270 \mathrm{mg} / \mathrm{L}^{-1}$ reported by Strasser et al. [44] from $B$. brongniartii in submerged culture. Amin et al. [45] produced red pigment from B. bassiana in submerged fermentation, reaching a yield of up to $480 \mathrm{mg} / \mathrm{L}$. In addition, a combination of spores and pigment increases the insecticidal activity, which suggests that the use of the biofilm bioreactor developed in the present research would help to obtain infective units and metabolites in a single step for their possible use in the biological control of pests in further in vitro experiments. The production dynamics of oosporein (Figure 4) is similar to that of carbon dioxide (Figure 3) and may be another alternative for estimating fungal growth, because the use of certain metabolic products may offer more sensitive results [46].

The results obtained in the characterization of the compounds show five ionized peaks (Figure 5) where oosporein was the only relevant metabolite detected. It was identified by information reported in the literature, with the formula $\mathrm{C}_{14} \mathrm{H}_{10} \mathrm{O}_{8}[1,15,16,44]$. The negative ionization of MS analysis allowed the identification of a compound with $\mathrm{m} / \mathrm{z} 305$. The result agrees with that reported by Feng et al. [15], who characterized the production of oosporein in fungi. They mentioned that oosporein is only ionized in negative mode. It was not possible to identify peaks 1-4, and other metabolites, such as tenellin, bassianin, or beauvericin produced by Beauveria species, were not found. Strasser et al. [44] considered that the production of oosporein is constitutive. Hence, B. bassiana $\mathrm{PQ} 2$ produced oosporein independently of the culture medium or the bioreactor.

The results of this research represent a viable and novel way to produce aerial conidia and oosporein from Beauveria bassiana PQ2 using a biofilm reactor. Some authors have reported goods yields in protein production (hydrophobin II) by Trichoderma reesei [20]. In addition, conidia and secondary metabolites produced by Aspergillus clavatus in a biofilm reactor have been shown to be effective in mosquito (Culex quinquefasciatus) control [28]. 


\section{Conclusions}

The $K_{L} a$ of the biofilm bioreactor showed high oxygen transfer in both liquid and gaseous phases. The designed bioreactor ensured the development of SmF and SSF at the same time and the production of both aerial conidia and oosporein by Beauveria bassiana $\mathrm{PQ2}$. The $\mathrm{CO}_{2}$ production dynamic allowed determining the fungal growth in the whole process. To our knowledge, this is the first report on the biomass estimation of $B$. bassiana through respirometry and the production of oosporein in a biofilm bioreactor. It represents a viable alternative for obtaining value-added products from filamentous fungi.

Supplementary Materials: The following are available online at https:/ /www.mdpi.com/article/10 .3390/jof7080582/s1, Figure S1: Evolution of oxygen solubility at different air flow-rates quantified by titration of liquid media with thiosulfate. Values of slope were used in Equation (1) for calculating Volumetric oxygen transfer coefficients $\left(K_{L} a\right)$ values, Figure S2: Invasion of metal solid support with mycelia and aerial conidia.

Author Contributions: H.R.L.-J. and J.G.Á.-H., conceptualization, methodology, and writing; L.V.R.D., writing, data curation, and formal analysis; M.R.M., writing and editing; J.E.W.-P., D.B.M.-M., and F.V., methodology and formal analysis; M.A.-Z., writing and review; J.A.A.-V., investigation and formal analysis; P.A.-Z., visualization, supervision, and funding acquisition. All authors have read and agreed to the published version of the manuscript.

Funding: This research was funded by TECNOLÓGICO NACIONAL DE MÉXICO, granted to CVU IT17A895-2021.

Conflicts of Interest: The authors declare no conflict of interest.

\section{References}

1. Da Costa Souza, P.N.; Bim Grigoletto, T.L.; Beraldo de Moraes, L.A.; Abreu, L.M.; Souza Guimarães, L.H.; Santos, C.; Ribeiro Galvão, L.; Gomes Cardoso, P. Production and chemical characterization of pigments in filamentous fungi. Microbiology 2016, 162, 12-22. [CrossRef]

2. Neera, D.K.; Ramana, K.V.; Sharma, R.K. Optimization of Monascus pigment production and its antibacterial activity. Int. J. Curr. Res. Biosci. Plant Biol. 2017, 4, 71-80. [CrossRef]

3. Barra-Bucarei, L.; González, M.G.; Iglesias, A.F.; Aguayo, G.S.; Peñalosa, M.G.; Vera, P.V. Beauveria bassiana multifunction as an endophyte: Growth promotion and biologic control of Trialeurodes vaporariorum, (Westwood) (Hemiptera: Aleyrodidae) in tomato. Insects 2020, 11, 591. [CrossRef]

4. Stracquadanio, C.; Quiles, J.M.; Meca, G.; Cacciola, S.O. Antifungal activity of bioactive metabolites produced by Trichoderma asperellum and Trichoderma atroviride in liquid medium. J. Fungi 2020, 6, 263. [CrossRef]

5. Soesanto, L.; Sari, L.Y.; Mugiastuti, E.; Manan, A. Cross application of entomopathogenic fungi raw secondary metabolites for controlling fusarium wilt of chili seedlings. Jurnal Hama Penyakit Tumbuhan Tropika 2021, 21, 82-90. [CrossRef]

6. Manan, M.; Webb, C. Design aspects of solid state fermentation as applied to microbial bioprocessing. J. Appl. Biotechnol. Bioeng. 2017, 4, 91. [CrossRef]

7. Hussain, A.; Tian, M.-Y.; Ahmed, S.; Shahid, M. Current status of entomopathogenic fungi as mycoinecticides and their inexpensive development in liquid cultures. In Zoologia; García, M.D., Ed.; InTech: Rijeka, Croatia, 2012; pp. 103-122.

8. Pradeep, F.S.; Begam, M.S.; Palaniswamy, M.; Pradeep, B. Influence of culture media on growth and pigment production by Fusarium moniliforme KUMBF1201 isolated from paddy field soil. World Appl. Sci. J. 2013, 22, 70-77. [CrossRef]

9. Cruz Barrera, M.; Gómez, M.I.; Serrato Bermúdez, J.C. Towards the production of fungal biocontrol candidates using inert supports: A case of study of Trichoderma asperellum in a pilot fixed bed fermenter. Biocontrol Sci. Technol. 2019, 29, 162-184. [CrossRef]

10. Méndez-González, F.; Loera-Corral, O.; Saucedo-Castañeda, G.; Favela-Torres, E. Bioreactors for the production of biological control agents produced by solid-state fermentation. In Current Developments in Biotechnology and Bioengineering; Pandey, A., Larroche, C., Soccol, C.R., Eds.; Elsevier: Amsterdam, The Netherlands, 2018; pp. 109-121.

11. Lohse, R.; Jakobs-Schönwandt, D.; Vidal, S.; Patel, A.V. Evaluation of new fermentation and formulation strategies for a high endophytic establishment of Beauveria bassiana in oilseed rape plants. Biological. Control 2015, 88, 26-36. [CrossRef]

12. Valencia, J.W.A.; Gaitán Bustamante, A.L.; Jiménez, A.V.; Grossi-de-Sá, M.F. Cytotoxic activity of fungal metabolites from the pathogenic fungus Beauveria bassiana: An intraspecific evaluation of beauvericin production. Curr. Microbiol. 2011, 63, 306. [CrossRef] [PubMed]

13. Mao, B.-Z.; Huang, C.; Yang, G.-M.; Chen, Y.-Z.; Chen, S.-Y. Separation and determination of the bioactivity of oosporein from Chaetomium cupreum. Afr. J. Biotechnol. 2010, 9. [CrossRef] 
14. Mwamburi, L.A.; Laing, M.D.; Miller, R.M. Laboratory screening of insecticidal activities of Beauveria bassiana and Paecilomyces lilacinus against larval and adult house fly (Musca domestica L.): Research article. Afr. Entomol. 2010, 18, 38-46. [CrossRef]

15. Feng, P.; Shang, Y.; Cen, K.; Wang, C. Fungal biosynthesis of the bibenzoquinone oosporein to evade insect immunity. Proc. Natl. Acad. Sci. USA 2015, 112, 11365. [CrossRef] [PubMed]

16. Alurappa, R.; Bojegowda, M.R.M.; Kumar, V.; Mallesh, N.K.; Chowdappa, S. Characterisation and bioactivity of oosporein produced by endophytic fungus Cochliobolus kusanoi isolated from Nerium oleander L. Nat. Prod. Res. 2014, 28, $2217-2220$. [CrossRef]

17. Nagaoka, T.; Nakata, K.; Kouno, K. Antifungal activity of oosporein from an antagonistic fungus against Phytophthora infestans. Z. Nat. C 2004, 59, 302-304. [CrossRef]

18. Ramesha, A.; Venkataramana, M.; Nirmaladevi, D.; Gupta, V.K.; Chandranayaka, S.; Srinivas, C. Cytotoxic effects of oosporein isolated from endophytic fungus Cochliobolus kusanoi. Front. Microbiol. 2015, 6, 870. [CrossRef]

19. Koch, E.; Ole Becker, J.; Berg, G.; Hauschild, R.; Jehle, J.; Köhl, J.; Smalla, K. Biocontrol of plant diseases is not an unsafe technology! J. Plant Dis. Prot. 2018, 125, 121-125. [CrossRef]

20. Khalesi, M.; Zune, Q.; Telek, S.; Riveros-Galan, D.; Verachtert, H.; Toye, D.; Gebruers, K.; Derdelinckx, G.; Delvigne, F. Fungal biofilm reactor improves the productivity of hydrophobin HFBII. Biochem. Eng. J. 2014, 88, 171-178. [CrossRef]

21. Musoni, M.; Destain, J.; Thonart, P.; Bahama, J.-B.; Delvigne, F. Bioreactor design and implementation strategies for the cultivation of filamentous fungi and the production of fungal metabolites: From traditional methods to engineered systems. Biotechnol. Agron. Soc. Environ. 2015, 19, 430-442.

22. Moutafchieva, D.; Popova, D.; Dimitrova, M.; Tchaoushev, S. Experimental determination of the volumetric mass transfer coefficient. J. Chem. Technol. Metall. 2013, 48, 351-356.

23. Aguilar-Zárate, P.; Wong-Paz, J.E.; Rodríguez-Duran, L.V.; Buenrostro-Figueroa, J.; Michel, M.; Saucedo-Castañeda, G.; FavelaTorres, E.; Ascacio-Valdés, J.A.; Contreras-Esquivel, J.C.; Aguilar, C.N. On-line monitoring of Aspergillus niger GH1 growth in a bioprocess for the production of ellagic acid and ellagitannase by solid-state fermentation. Bioresour. Technol. 2018, 247, 412-418. [CrossRef] [PubMed]

24. Cooper, C.; Fernstrom, G.; Miller, S. Performance of agitated gas-liquid contactors. Ind. Eng. Chem. 1944, 36, 504-509. [CrossRef]

25. Garcia-Ochoa, F.; Gomez, E. Bioreactor scale-up and oxygen transfer rate in microbial processes: An overview. Biotechnol. Adv. 2009, 27, 153-176. [CrossRef]

26. De la Cruz-Quiroz, R.; Roussos, S.; Aguilar, C.N. Production of a biological control agent: Effect of a drying process of solid-state fermentation on viability of Trichoderma spores. Int. J. Green Tech. 2018, 4, 1-6.

27. Aguilar-Zarate, P.; Cruz-Hernandez, M.A.; Montañez, J.C.; Belmares-Cerda, R.E.; Aguilar, C.N. Enhancement of tannase production by Lactobacillus plantarum CIR1: Validation in gas-lift bioreactor. Bioprocess Biosyst. Eng. 2014, 37, $2305-2316$. [CrossRef] [PubMed]

28. Seye, F.; Bawin, T.; Boukraa, S.; Zimmer, J.-Y.; Ndiaye, M.; Delvigne, F.; Francis, F. Pathogenicity of Aspergillus clavatus produced in a fungal biofilm bioreactor toward Culex quinquefasciatus (Diptera: Culicidae). J. Pestic. Sci. 2014, 39, 127-132. [CrossRef]

29. Zune, Q.; Delepierre, A.; Gofflot, S.; Bauwens, J.; Twizere, J.C.; Punt, P.J.; Francis, F.; Toye, D.; Bawin, T.; Delvigne, F. A fungal biofilm reactor based on metal structured packing improves the quality of a Gla::GFP fusion protein produced by Aspergillus oryzae. Appl. Microbiol. Biotechnol. 2015, 99, 6241-6254. [CrossRef]

30. Kang, S.W.; Lee, S.H.; Yoon, C.S.; Kim, S.W. Conidia production by Beauveria bassiana (for the biocontrol of a diamondback moth) during solid-state fermentation in a packed-bed bioreactor. Biotechnol. Lett. 2005, 27, 135. [CrossRef] [PubMed]

31. Pham, T.A.; Kim, J.J.; Kim, K. Optimization of solid-state fermentation for improved conidia production of Beauveria bassiana as a mycoinsecticide. Mycobiology 2010, 38, 137-143. [CrossRef]

32. Mascarin, G.M.; Jackson, M.A.; Kobori, N.N.; Behle, R.W.; Dunlap, C.A.; Delalibera Júnior, Í. Glucose concentration alters dissolved oxygen levels in liquid cultures of Beauveria bassiana and affects formation and bioefficacy of blastospores. Appl. Microbiol. Biotechnol. 2015, 99, 6653-6665. [CrossRef] [PubMed]

33. Santa, H.S.D.; Santa, O.R.D.; Brand, D.; Vandenberghe, L.P.d.S.; Soccol, C.R. Spore production of Beauveria bassiana from agro-industrial residues. Braz. Arch. Biol. Technol. 2005, 48, 51-60. [CrossRef]

34. Damiani, A.L.; Kim, M.H.; Wang, J. An improved dynamic method to measure kLa in bioreactors. Biotechnol. Bioeng. 2014, 111, 2120-2125. [CrossRef] [PubMed]

35. Nogueira, R.; Lazarova, V.; Manem, J.; Melo, L.F. Influence of dissolved oxygen on the nitrification kinetics in a circulating bed biofilm reactor. Bioprocess Eng. 1998, 19, 441-449. [CrossRef]

36. Pérez, J.; Montesinos, J.L.; Gòdia, F. Gas-liquid mass transfer in an up-flow cocurrent packed-bed biofilm reactor. Biochem. Eng. J. 2006, 31, 188-196. [CrossRef]

37. García-Gutiérrez, C.; González-Maldonado, M.B.; Medrano-Roldán, H.; Solís-Soto, A. Study of the mixing conditions in bioreactor for blastospores production of Beauveria bassiana. Rev. Colombiana Biotecnol. 2013, 15, 47-54.

38. Kurt, T.; Marbà-Ardébol, A.-M.; Turan, Z.; Neubauer, P.; Junne, S.; Meyer, V. Rocking Aspergillus: Morphology-controlled cultivation of Aspergillus niger in a wave-mixed bioreactor for the production of secondary metabolites. Microbial. Cell Factories 2018, 17, 128. [CrossRef]

39. Pavlík, M.; Fleischer, P.; Fleischer, P.; Pavlík, M.; Šuleková, M. Evaluation of the carbon dioxide production by fungi under different growing conditions. Curr. Microbiol. 2020, 77, 2374-2384. [CrossRef] 
40. Da Cunha, L.P.; Casciatori, F.P.; Vicente, I.V.; Garcia, R.L.; Thoméo, J.C. Metarhizium anisopliae conidia production in packed-bed bioreactor using rice as substrate in successive cultivations. Process Biochem. 2020, 97, 104-111. [CrossRef]

41. Song, M.H.; Yu, J.S.; Kim, S.; Lee, S.J.; Kim, J.C.; Nai, Y.-S.; Shin, T.Y.; Kim, J.S. Downstream processing of Beauveria bassiana and Metarhizium anisopliae-based fungal biopesticides against Riptortus pedestris: Solid culture and delivery of conidia. Biocontrol Sci. Technol. 2019, 29, 514-532. [CrossRef]

42. Sala, A.; Artola, A.; Sánchez, A.; Barrena, R. Rice husk as a source for fungal biopesticide production by solid-state fermentation using B. bassiana and T. harzianum. Bioresour. Technol. 2020, 296, 122322. [CrossRef]

43. Ávila-Hernández, J.; Carrillo-Inungaray, M.; De-La-Cruz-Quiroz, R.; Wong-Paz, J.; Muñiz-Márquez, D.; Parra, R.; Aguilar, C.; Aguilar-Zárate, P. Beauveria bassiana secondary metabolites: A review inside their production systems, biosynthesis, and bioactivities. Mex. J. Biotechnol. 2020, 5, 1-33. [CrossRef]

44. Strasser, H.; Abendstein, D.; Stuppner, H.; Butt, T.M. Monitoring the distribution of secondary metabolites produced by the entomogenous fungus Beauveria brongniartii with particular reference to oosporein. Mycol. Res. 2000, 104, 1227-1233. [CrossRef]

45. Amin, G.A.; Youssef, N.A.; Bazaid, S.; Saleh, W.D. Assessment of insecticidal activity of red pigment produced by the fungus Beauveria bassiana. World J. Microbiol. Biotechnol. 2010, 26, 2263-2268. [CrossRef]

46. Ng, H.E.; Raj, S.S.A.; Wong, S.H.; Tey, D.; Tan, H.M. Estimation of fungal growth using the ergosterol assay: A rapid tool in assessing the microbiological status of grains and feeds. Lett. Appl. Microbiol. 2008, 46, 113-118. [CrossRef] 